\title{
Photocatalytic Anti-Markovnikov Hydroetherification
}
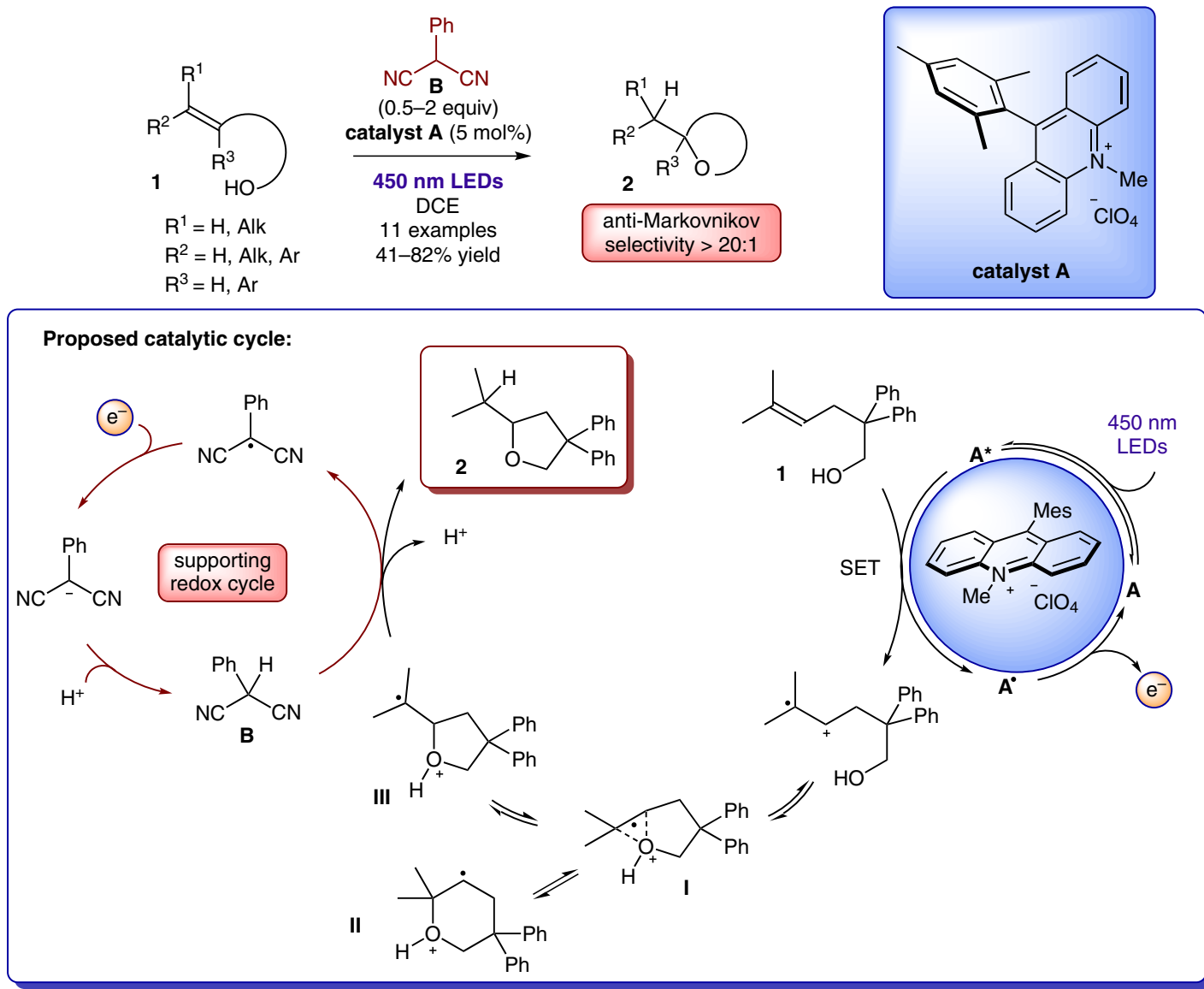

Significance: A direct photocatalytic antiMarkovnikov hydroetherification has been described by the Nicewicz group. The reported procedure is promoted by the commercially available sensitizer 9-mesityl-10-methylacridinium perchlorate $(\mathbf{A})$ and the $\mathrm{H}$-atom donor 2-phenylmalonitrile (B). The authors suggest that the methodology is based on two different redox cycles. A primary one, which initiates the reaction by a single-electron transfer (SET) and a supporting one, which simultaneously facilitates the hydrogen exchange and serves as an electron-redox mediator.

SYNFACTS Contributors: Benjamin List, Mattia Riccardo Monaco Synfacts 2013, 9(1), $0101 \quad$ Published online: 17.12.2012 Dol: 10.1055/s-0032-1317903; Reg-No.: B11612SF
Comment: The study of catalytic anti-

Markovnikov additions of nucleophiles to olefins has gained great interest in the last decades since it had been described as one of the 'top ten challenges for catalysis' [J. Haggin Chem. Eng. News 1993, 71 (22), 23]. In this work, the authors describe the addition of alcohols to alkenes via a newly developed two-component organic photoredox catalytic system. The reaction affords a wide range of cyclic ethers with complete selectivity, which reflects the thermodynamic equilibrium between the three radical intermediates I, II and III. 